\title{
Educação ambiental e unidades de conservação: um estudo sobre a Comunida- de Guaié, na Área de Proteção Ambiental (APA) do estuário do Rio Ceará
}

\author{
Karinne Wendy Santos de Menezes ${ }^{1}$, Aline Neris de Carvalho Maciel $^{2}$ e \\ Geise Paula de Sousa ${ }^{3}$
}

\footnotetext{
1 Mestranda do Programa de Pós-Graduação em Geografia, Universidade Estadual do Ceará - UECE. E-mail: karinnewendy@gmail.com

2 Mestranda do Programa de Pós-Graduação em Desenvolvimento e Meio Ambiente, Universidade Federal do Ceará - UFC. E-mail: alinenerisdecarvalho@gmail.com

3 Graduada em Ciências Ambientais, Departamento Ciências do Mar (LABOMAR), Universidade Federal do Ceará - UFC. E-mail: geisinha.ps@gmail.com
}

Resumo: 0 presente trabalho se propõe a analisar a comunidade Guaié que está localizada, naAPA do Estuário do Rio Ceará, em Caucaia-CE. Esta pesquisa debate a situação na qual estão inseridos e a relação da comunidade com 0 ambiente protegido. Investiga-se, esta área pelas suas problemáticas e relevância ambiental. Para o embasamento teórico-metodológico foram realizados levantamentos bibliográficos, pesquisa documental e trabalhos de campo. Os estudos sobre esta unidade de conservação de uso sustentável são imprescindíveis para a compreensão das relações sociais com o meio natural, pois a área analisada possui deficiências habitacionais, e contradições nas formas de uso e ocupação.

Palavras-chaves: Preservação; Comunidade; APA; Guaié; Rio Ceará.

\begin{abstract}
This study aims to analyze the Guaie community that is located in the APA of Ceará River Estuary in Caucaia -CE. This research discusses the situation in which they are inserted and community relationship with the protected environment. Investigates this area for its problems and environmental relevance. For the theoretical and methodological basis were carried out bibliography, documentary research and field work. The studies on the sustainable use conservation unit are essential for understanding the social relationships with the natural environment, since the area has analyzed housing deficiencies and contradictions in the forms of use and occupation.
\end{abstract}

Keywords: Preservation; Community; APA; Guaié; Ceará River.

Sumário: 1 Introdução - 2 Sistema Nacional de Unidades de Conservação (SNUC) - 3 Educação Ambiental - Breve Histórico Mundial e Nacional - 4 Área de Proteção Ambiental (APA) 5 A Comunidade Guaié da APA do Estuário do Rio Ceará: 5.1 Bairro, Favela ou Comunidade; 5.2 Os sistemas ambientais do Guaié; 5.3 A relação da comunidade com a APA do estuário do Rio Ceará - 6 Considerações Finais - Referências.

\section{INTRODUÇÃO}

A Área de Proteção Ambiental do Estuário do Rio Ceará, foi criada no ano de 1999 pelo

Planeta Amazônia: Revista Internacional de Direito Ambiental e Políticas Públicas 
decreto № 25.413, é uma unidade de conservação de uso sustentável, em um ambiente costeiro e semifechado, e abrange uma área de, aproximadamente, 500 hectares de manguezal. Está localizada na Região M etropolitana de Fortaleza, mais precisamente, na divisa dos municípios de Fortaleza e Caucaia, no estado do Ceará. (SEM ACE, 2015).

A comunidade Guaié, localiza-se no bairro Iparana, em Caucaia, nos limites da unidade de conservação. Para compreender a relação entre a comunidade e o ambiente protegido, foram realizados levantamentos bibliográficos, pesquisa documental e trabalhos de campo para reconhecimento da área de estudo.

0 objetivo deste trabalho é analisar a área de proteção ambiental do estuário do rio Ceará na qual a comunidade do Guaié está localizada, suas representações, histórias, processos e acesso a infraestrutura, fazendo-se uma relação entre sociedade - natureza, para uma gestão territorial integrada e participativa.

Primeiramente, discutiram-se temas pertinentes as unidades de conservação e educação ambiental, para posteriormente discutir sobre o contexto no qual a comunidade está inserida e a sua relação com o ambiente, com o intuito de entender quais são as relações estabelecidas entre comunidade e a área de preservação ambiental.

A figura 01 refere-se ao mapa de localização da Comunidade Guaié, na Área de Proteção Ambiental (APA) do Estuário do Rio Ceará, no município de Caucaia-CE.

Figura 01 - Mapa de Localização da Comunidade Guaié, na APA do Estuário Rio Ceará.

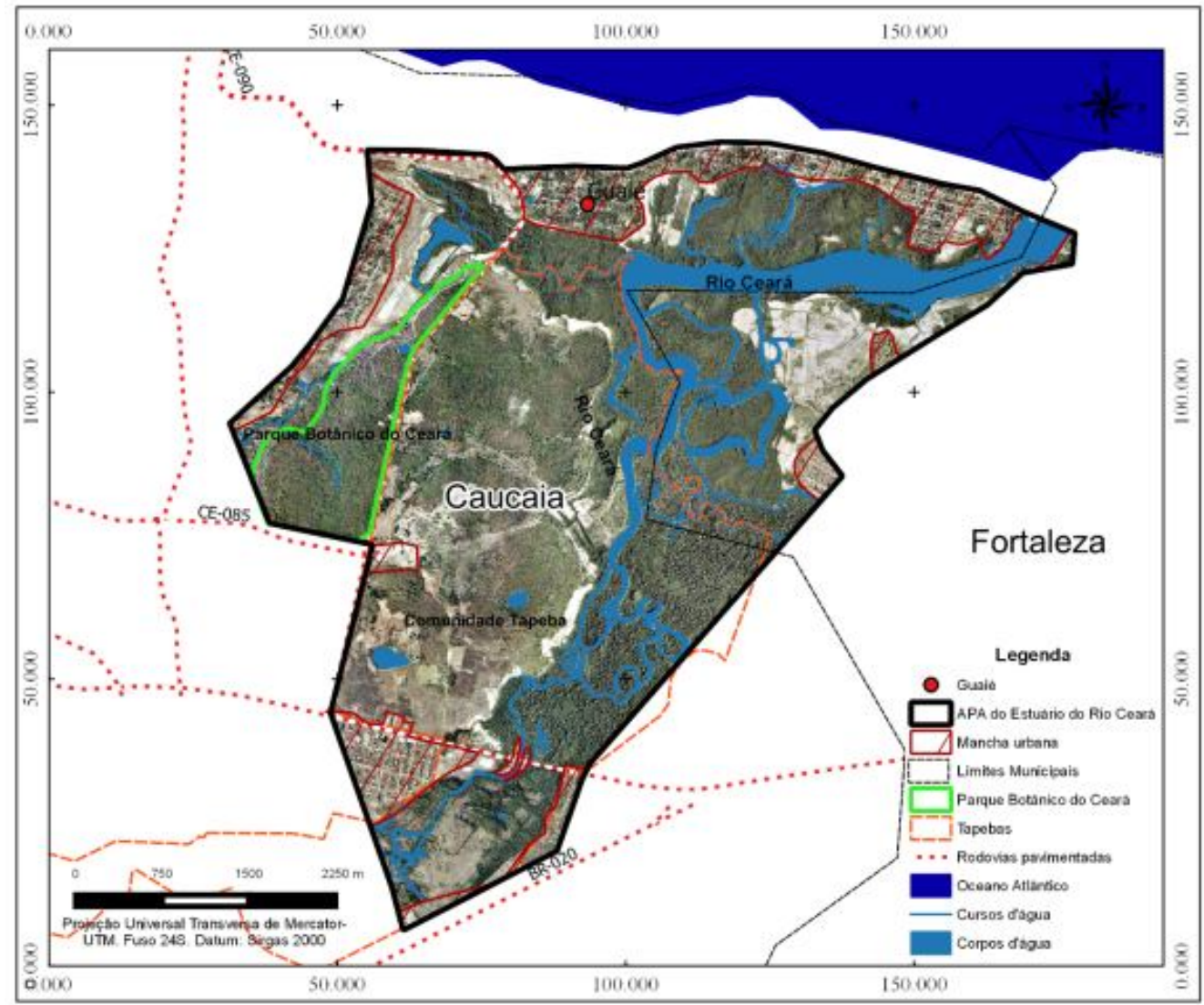

Fonte: Menezes (2016). 


\section{SISTEMA NACIONAL DE UNIDADES DE CONSERVAÇÃO (SNUC)}

A criação do Sistema Nacional de Unidade de Conservação ocorreu através da lei 9.985 no ano 2000. É uma legislação específica e pioneira para criação, normatização e planejamento das unidades de conservação (UC). Depois de oito anos de tramitação na Casa Legislativa. O novo sistema vem consolidar uma série de normas e discussão acerca das Unidades de Conservação, suas diversas categorias e sua forma de implantação e manejo. Esta normativa trouxe como grande mudança de nomenclatura o termo "área de proteção" para "unidade de conservação". (SILVA, 2008).

Sendo que o termo UC foi definido no SNUC como:

Espaço territorial e seus recursos ambientais, incluindo as águas jurisdicionais, com características naturais relevantes, legalmente instituído pelo poder público, com objetivos de conservação e limites definidos. Sob regime especial de administração ao qual se aplicam garantias adequadas de proteção (SNUC, 2000).

Essas Unidades surgiram com a finalidade de proteger a biodiversidade, sendo agrupadas em duas subdivisões: UC de proteção integral e UC de uso sustentável. (M EZZOM O et al, 2014).

Nas unidades de proteção integral é designado a preservação da natureza com o uso indireto dos recursos da natureza. $\mathrm{E}$ a categoria de uso sustentável busca conciliar o uso sustentável com proteção do meio ambiente.

As categorias pertinentes a UC de Uso Sustentável são: área de proteção ambiental, área de relevante interesse ecológico, floresta nacional, reserva extrativista, reserva de fauna, reserva de desenvolvimento sustentável e reserva particular do patrimônio natural. (SNUC, 2000)

\section{EDUCAÇÃO AM BIENTAL: BREVE HISTÓRICO MUNDIAL E NACIONAL}

Um dos grandes eventos precursores da criação e disseminação da Educação Ambiental (EA) foi a Conferência sobre M eio Ambiente Humano, realizado pela Organização das Nações Unidas (ONU), em Estocolmo, na Suécia, na década de 70. Cujo objetivo era confeccionar uma declaração onde se utilizaria a EA como importante ferramenta para superar a crise ambiental estabelecida. Posteriormente, ocorreu o Seminário de Belgrado, onde o principal foco foi divulgar a relevância de uma política de Educação Ambiental de âmbito regional e internacional. 0 documento produto deste encontro foi nomeado como Carta de Belgrado, onde esse define os princípios básicos de EA (TOZONI, 2004).

Já na década de 90, a Conferência das Nações Unidas sobre M eio Ambiente, conhecida como Rio-92, debateu os eixos de organização de EA, reorientação do ensino para o desenvolvimento sustentável, aumento da consciência pública e promoção do treinamento. A proposta desse evento foi estipular que EA deve estar voltada ao desenvolvimento sustentável, seja no ensino formal ou informal (TOZONI, 2004). 
Nesse contexto, no Brasil, foi criado o Plano Nacional de Educação Ambiental (PNEAlei 9795/99), implementado pelo M inistério do M eio Ambiente, a fim de iniciar as atividades e programas para E.A. 0 ensino promovido é o ensino interdisciplinar no ensino formalinformal.

Apesar de no Brasil existir a ideia de leis que "não pegam", uma lei existe para ser cumprida ou questionada, de modo que, logo após a promulgação da Política Nacional de Educação Ambiental (PNEA), foi criada no Ministério da Educação a Coordenação Geral de Educação Ambiental e no Ministério do M eio Ambiente, a Diretoria de Educação Ambiental como instâncias de execução da PNEA.(SORRENTINO et al, 2005, p.290)

A agenda 21 do Brasil foi o produto final das conferências, debatendo as questões educacionais fundamentais para a preservação dos recursos naturais, e repensando a ética ambiental. (LEITE e M EDINA, 2001). Outros eventos continuaram com o debate sobre desenvolvimento ambiental. Dentre estes temos a Cúpula de Brasília, a Rio+10, Rio+15, Rio +20 e mais recente a COP- 21 .

\section{4 ÁREA DE PROTEÇÃO AMBIENTAL (APA)}

Este trabalho propõe-se a analisar a comunidade Guaié localizada em uma Área de Proteção Ambiental. As APA têm por objetivos: proteger a diversidade biológica, disciplinar 0 processo de ocupação e assegurar a sustentabilidade no uso dos recursos naturais (SNUC, 2000).

Os critérios para classificação de uma APA são: o uso e a ocupação humana, sendo disciplinados pela legislação e órgãos ambientais competentes, locais dotados de atributos abióticos, bióticos, estéticos ou culturais especialmente importantes para a qualidade de vida e 0 bem-estar das populações humanas (SNUC, 2000).

\section{A COMUNIDADE GUAIÉ NA APA DO ESTUÁRIO DO RIO CEARÁ}

\subsection{Bairro, Favela ou Comunidade}

Para compreender quem são os Guaiés, o contexto no qual eles estão inseridos e a relação da comunidade com o ambiente, foi preciso buscar algumas definições que auxiliassem nessa busca, e surgiu o seguinte questionamento quanto à localização do limite territorial: moram em um bairro? Uma favela? Uma comunidade?

Na pesquisa realizada, não foi encontrada a descrição da delimitação da comunidade Guaié. Contudo, o documento que cria e delimita os Bairros do Município de Caucaia, a partir da Lei $N^{\circ} 2.057$, de 10 de setembro de 2009, faz a seguinte delimitação do bairro de Iparana, em Caucaia-CE: 
[...] tem como ponto inicial o prolongamento da Rua 12 no Oceano Atlântico; deste ponto inicial, segue pelo prolongamento citado e pela Rua 12, Avenida Ulisses Guimarães, Rua Sem Denominação, Rua das Salinas, e o seu prolongamento até o rio Ceará, rio Ceará, córrego do Façanha, estrada José Aragão e Albuquerque (Rodovia CE090), Avenida Ulisses Guimarães, Rua Sem denominação, Rua Santo Onofre até o Oceano Atlântico; daí, segue pela orla do oceano Atlântico até confrontar com a Rua 12; daí, segue até alcançar o ponto inicial. (CAUCAIA, 2009)

A partir da delimitação expressa nesse documento, acredita-se que a comunidade está inserida nos limites do bairro Iparana, pois na pesquisa documental realizada, não encontramos uma delimitação oficial que à delimitasse minuciosamente.

Nos trabalhos de campo verificaram-se padrões de habitações subnormais, o que nos fez questionar se os Guaiés são uma comunidade ou uma favela. Para contribuirmos com essa breve discussão utilizamos as considerações de Valladares (2005) e Araújo (2010).

As favelas aparecem na cidade como território da violência e da pobreza, da ilegalidade quando compara à cidade legada, são percebidas como o outro lado da cidade. Percebida atualmente como um fenômeno tipicamente urbano. Guimarães apud Valladares (2005) indica que a definição de favela tem como ponto de partida "os aglomerados que o consenso público classifica como tal, estejam situados no morro ou em qualquer outra parte", para a conceituação de favelas.

0 autor utiliza cinco critérios para conjuntos de construções ou aglomerados para resumir o processo de definição dos bairros conhecidos como favelas foram incluídos os aglomerados humanos que possuíssem as seguintes características:

1. Proporções mínimas - Agrupamentos prediais ou residenciais formados com unidades de número geralmente superior a 50 ;

2. Tipo de habitação - Predominância no agrupamento, de casebres ou barracões de aspecto rústico típico, construídos principalmente de folhas de Flandres, chapas zincadas, tábuas ou materiais semelhantes.

3. Condição jurídica de ocupação - Construções sem licenciamento e sem fiscalização, em terrenos de terceiros ou de propriedade desconhecida;

4. Melhoramentos Públicos - Ausência no todo ou em parte, de rede sanitária, luz, telefone e água encanada;

5. Urbanização - Área não urbanizada, com falta de arruamento, numeração ou emplacamento. (GUIMARÃES, apud, VALADARES, 2005)

O mosaico de imagem a seguir mostra os contrastes nos tipos de habitação existentes nesta comunidade. 
Figura 02 - Composição de fotografia com diferentes tipos de habitações no Guaié.

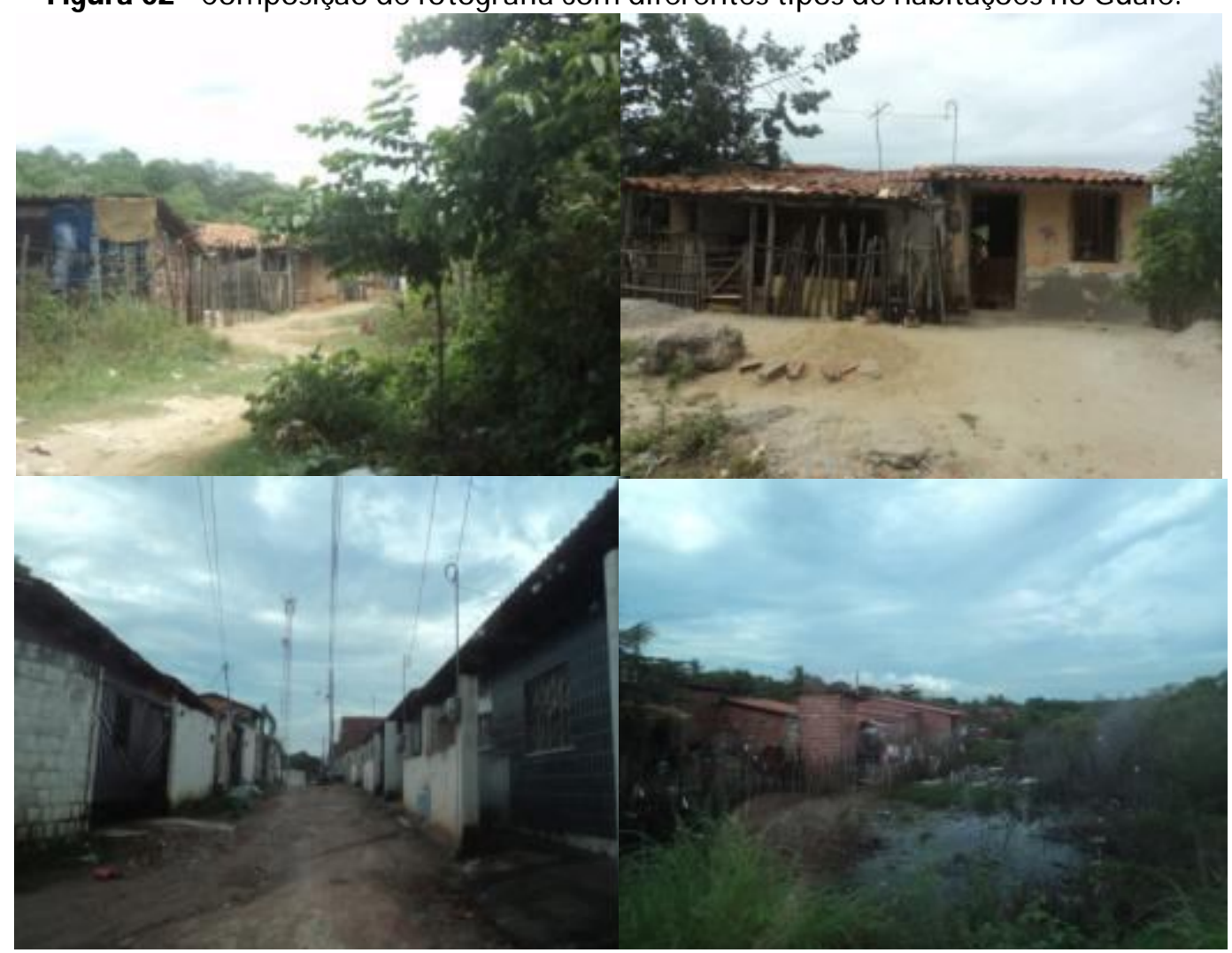

Fonte: M ENEZES, 2014.

O que levou a pensar no Guaié inserido no processo de favelização foi o caráter das habitações, e a ausência e/ ou a precariedade de infraestruturas existentes, como saneamento básico, com dificuldades de acesso. Todas essas problemáticas são potencializadas por estarem situados no entorno da planície fluviomarinha do Rio Ceará, em uma área de preservação ambiental.

As grandes cidades e metrópoles apresentam extensa paisagem degradada, social e ambientalmente, pelo tipo de território das favelas, pela precariedade do habitar (com baixíssima qualidade de moradia) e pela violência urbana crescente. Esse é o aspecto empírico da favela, sua expressão material, bem mais fácil de compreensão do que o processo de empobrecimento dos trabalhadores. (ARAÚj0, 2010, p. 116)

As favelas não são homogêneas e nem são compostas basicamente por habitações precárias, e esta análise mostra que a comunidade Guaié está inserida nesse processo de favelização, com os contrastes nos tipos de habitação e carência de equipamentos urbanos.

A partir das contribuições de Valladares (2005), compreende-se que a categoria "comunidade" ameniza a estigmatização causada pelas favelas.

0 que faz entender que os "Guaié" quanto comunidade são as formas de se relacionar com 0 ambiente e a sua representatividade social, pois eles se sentem pertencentes ao lugar e lutam pelo direito à moradia. Consideram-se, desta forma, uma comunidade. 


\subsection{Os sistemas ambientais do Guaié}

Os sistemas ambientais são identificados levando em consideração as inter-relações, dimensões e as características de origem e evolução, para assim identificar as suas potencialidades e limitações, para melhor avaliar a capacidade de suporte ao uso e ocupação da terra (SOUZA, 2009).

Na comunidade Guaié foi identificado o sistema ambiental da planície litorânea, tendo com subsistema principal, a planície fluviomarinha com manguezais. "As planícies fluviomarinha são ambientes especiais, sendo submetidos às influências de processos marinhos (oscilações de maré) e fluviais" (SOUZA, 2009).

É ao longo da planície fluviomarinha do Rio Ceará que está à maior parcela de ocupação da comunidade Guaié.

0 mangue é constantemente devastado para a retirada de madeira lenhosa que serve como matriz energética e para a construção civil. $A$ atividade salineira teve grande impacto nos manguezais dos rios Ceará, Cocó e Pacoti. Em meados da segunda metade do século XX, grandes áreas de mangue daqueles rios foram devastadas e incorporadas à atividade. A expansão urbana invadindo essas áreas, para fins de moradia ou empreendimentos turísticos e industriais, impactaram irreversivelmente 0 sistema ambiental. (SOUZA, 2009, p.56)

Nas pesquisas realizadas em campo constatamos que as salinas existentes no rio Ceará estão desativadas desde meados da década de 1980, alguns moradores associam a desativação ao crescimento da produção de sal em outros estados do Nordeste. Neste período ocorreram no bairro Iparana e nas proximidades da APA, conflitos pela posse de terras, e algumas famílias passaram a ocupar as áreas que correspondem atualmente ao território em que se situam os Guaié, mas muitas famílias já viviam no entorno da planície fluviomarinha do Rio Ceará.

A expansão da comunidade Guaié foi intensificada após esse período, por isso a necessidade de preservação e gestão sustentável destes ambientes. Na pesquisa não foram constatadas, por causa das dificuldades encontradas em campo, o número de famílias que vivem na área.

Sabe-se que existem moradores que vivem próximo ao rio Ceará há mais de 50 anos, e moram neste local desde que nasceram, mas que não souberam informar quais são as suas origens mais distantes, pois seus familiares também moraram e/ou moram nessas áreas, e viveram os conflitos e as contradições existentes da comunidade, e relatam a falta de interesse do governo e da prefeitura do município de Caucaia com a área.

Uma das situações mais críticas existentes na área referentes à gestão governamental, diz respeito a sua própria existência, pois, não foi encontrado na pesquisa de campo documento que respaldasse as informações sobre a comunidade ou que delimitasse o seu perímetro, ou a definisse como bairro, favela ou comunidade. 


\title{
5.3 A relação da comunidade com a APA do estuário do Rio Ceará
}

Para compreender como a comunidade Guaié está relacionada ao estuário, faz-se necessário entender a relação entre a sociedade e a natureza, pois essa ideia, do que é natureza, também é construída culturalmente.

De acordo com Costa et. al (2005) as populações que vivem no entorno da Área de Proteção Ambiental do Estuário do Rio Ceará é composta, principalmente, por índios da etnia Tapeba e por pessoas que são originárias do interior do estado do Ceará e da Região M etropolitana de Fortaleza, que se instalam em áreas de risco e sujeitas a inundações periódicas.

\begin{abstract}
Por tratar-se de uma APA (Área de Proteção Ambiental), existe um certo conflito, pois equipamentos urbanos como postes e redes de eletrificação estão sendo implantadas no antigo campo de salinas, descaracterizando o ecossistema e dando subsídios para que outros adentrem inclusive habitando as áreas de risco. A água utilizada pela comunidade é contaminada e de má qualidade acarretando diversas doenças que prejudicam em maior teor as crianças e os idosos. (COSTA et. al., 2005)
\end{abstract}

Segundo a Semace (2015), as principais atividades exercidas nesta área de preservação estão associadas diretamente com a utilização de seus recursos naturais, para a pesca e a captura de moluscos e crustáceos. As populações também complementam a sua renda familiar com trabalhos informais, como serviços de pedreiro, doméstica, artesanato, entre outros, ressaltamos que tanto as comunidades dos bairros Iparana e Parque Leblon, quando da Barra do Ceará e do Vila Velha utilizam os recursos provenientes do APA do Estuário do rio Ceará.

Nas imagens a seguir podemos visualizar algumas atividades exercidas na área de preservação ambiental.

A seguir imagens do local popularmente conhecido como "Recanto do Mangue", um local frequentado por moradores de Caucaia e Fortaleza para atividades de lazer e para a pesca artesanal.

Figura 03 - Estuário do Rio Ceará.

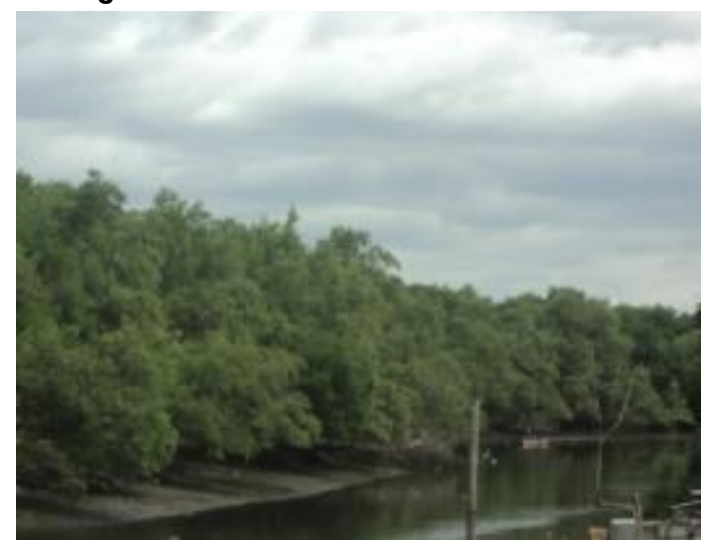

Fonte: M ENEZES, 2014.
Figura 04 - Pescadores no rio Ceará.

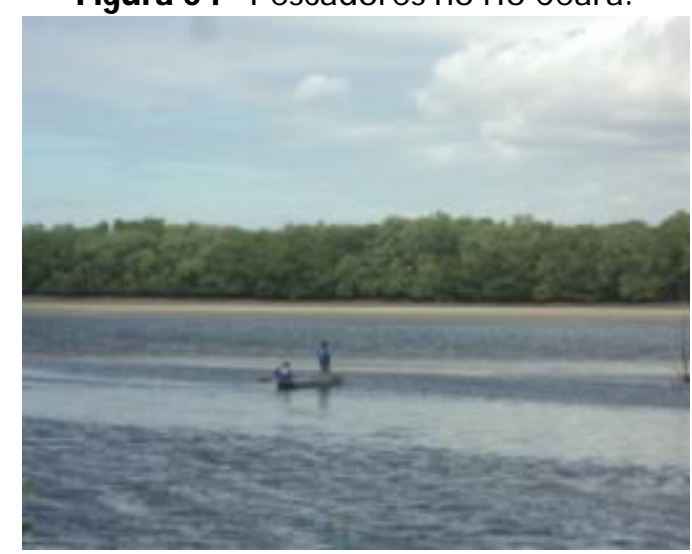

Fonte: M ENEZES, 2014. 
Figura 05 - Recanto do mangue.

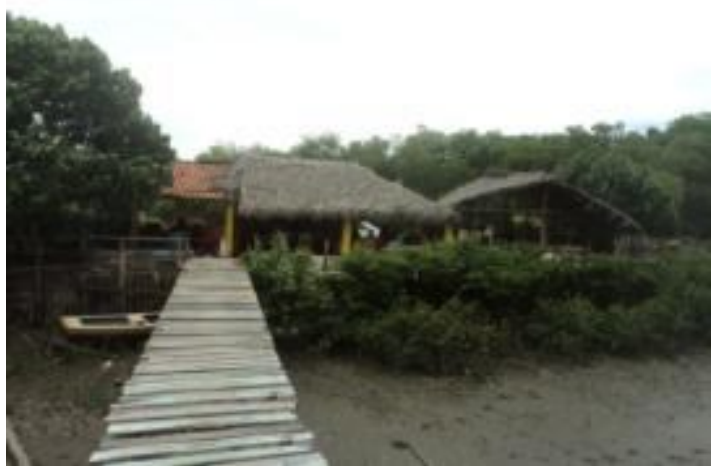

Fonte: MENEZES, 2014.
Figura 06 - Barcos para passeio e pesca.

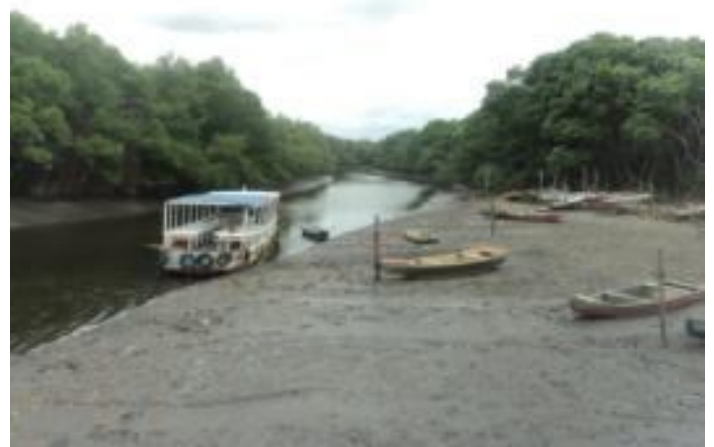

Fonte: MENEZES, 2014.

Nos últimos anos, o recanto foi inserido nas rotas de passeio realizado desde a Barra do Ceará até o rio, apesar de o público ser em sua maioria residente entre os municípios de Fortaleza e Caucaia, turistas têm se interessado em conhecer esta área.

\section{CONSIDERAÇÕES FINAIS}

A análise da comunidade Guaié foi fundamental para compreendermos a relação sociedade e natureza a partir do processo de produção do espaço, pois ressalta-se também, 0 direito à moradia, pois várias são as razões que as fazem permanecer neste ambiente. A comunidade Guaié é mais um grupo social que está incluso perversamente neste contexto de (re) produção do espaço.

Observa-se outra problemática, como se trata de uma comunidade sem definição legal e documentação regulamentada em órgãos ambientais, como poderá ser realizado um ordenamento territorial para que a gestão dessa APA possa ser eficiente? Logo, à necessidade de regulamentação da comunidade Guaié, não só por questão legalljurídica, mas também no intuito de preservação, gestão territorial e ambiental.

Como foi levantado no texto, anteriormente, a caracterização de favela devido a precariedade das habitações, e a ausência e deficiências como de infraestruturas existentes, como saneamento básico, com dificuldades de acesso; todas essas limitações estão associadas a uma planície flúviomarinha o que pode acarretara diversos impactos adversos como: contaminação de lençol freático, estabilização de dunas móveis e poluição por resíduos sólidos.

A partir da gestão territorial, as potencialidades e fragilidades socioambientais podem ser analisadas e medidas mitigadoras podem ser efetivadas. Percebe-se que a comunidade utiliza o meio natural para suas atividades de lazer e economia, já que não só os nativos, mas também turistas utilizam o mesmo espaço, o que mostra a importante atenção para esta unidade de conservação, evitando futuros impactos e desgaste na capacidade de suporte ambiental, o que acarreta o declínio da qualidade ambiental da área. 


\section{REFERÊNCIAS}

ARAÚJO, A. M . M. Fortaleza, metrópole regional: trabalho, moradia e acumulação. Fortaleza: EDUECE, 2010.

CAUCAIA. Prefeitura Municipal. Lei $\mathbf{N}^{\circ}$ 2.057, de 10 de setembro de 2009. Disponível em: বttp:// www.caucaia.ce.gov.br/sessoes/secretarias/>Acesso em 13 de outubro de 2013.

COSTA, F. G. R. et al. Análise dos Impactos Ambientais, Resultantes do Uso e Ocupação das Áreas de Mangue do Estuário do rio Ceará-CE. Anais da 57ạ Reunião Anual da SBPC - Fortaleza, CE - Julho/2005.

LEITE, A. L. T. A.; M EDINA, N. M. Educação Ambiental: curso básico a distância: documentos e legislações da educação ambiental. 2. ed. Brasília: M inistério do M eio Ambiente, 2001.

MEZZOM O, M .M. et al. Caracterização geoecológica como subsídio para estudos ambientais em rppns: estudos de casos no paraná. Revista Árvore, Viçosa-MG, v.38, n.5, p.907-917, 2014.

PNEA. Política Nacional de Educação Ambiental. Disponível em: http://portal.mec.gov.br/ secad/arquivos/pdf/educacaoambiental/lei9795.pdf. Acesso em: 12 de fevereiro de 2016.

SEM ACE. Superintendência Estadual do M eio Ambiente. Área de Proteção Ambiental do Estuário do Rio Ceará. Disponível em: http://www.semace.ce.gov.br/2010/12/area-deprotecao-ambiental-do-estuario-do-rio-ceara/ .Acesso em: 16 de outubro de 2015.

SILVA, J.M.O. Monumento Natural das Falésias de Beberibe-CE: Diretrizes para Planejamento e Gestão Ambiental. Dissertação do Curso de Mestrado, Universidade Federal do Ceará, 2008.

SORRENTINO,M et al. Educação Ambiental como Política Pública. Educação e Pesquisa, São Paulo, v. 31, n. 2, p. 285-299, maio/ago. 2005.

SOUZA, M. J. N. De. NETO, J. M; SANTOS, J. De 0; GONDIM, M. S. Diagnóstico Geoambiental do Município de Fortaleza: Subsídios ao Macrozoneamento Ambiental e à Revisão do Plano Diretor Participativo-PDPFor. Fortaleza: Prefeitura M unicipal de Fortaleza, 2009.

SNUC - BRASIL. Congresso. Senado. Lei no 9.985, de julho de 2000. Regulamenta 0 art. 225 da Constituição Federal, institui O Sistema Nacional de Unidades de Conservação da Natureza e dá outras providências. Diário Oficial (da) República Federativa do Brasil, Brasília, DF,18 de julho, 2000.

TOZONI-REIS, M. F. C. R. Educação Ambiental: natureza, razão e história. Campinas, SP: Autores associados, 2004 (Coleção Educação Contemporânea).

VALLADARES, L. Do. P. A Invenção da Favela. Do mito de origem à favela.com. Rio de Janeiro: Editora da FGV, 2005.

Artigo recebido em 26 de agosto de 2016.

Aprovado em 31 de dezembro de 2016. 